\title{
Acrofacial dysostosis, Kennedy-Teebi type
}

INSERM

\section{Source}

INSERM. (1999). Orphanet: an online rare disease and orphan drug data base. Acrofacial dysostosis, Kennedy-Teebitype. ORPHA:64542

Acrofacial dysostosis, Kennedy-T eebi type was reported as a new type of acrofacial dysostosis (see this term) due to the presence of manifestations not usually seen in Nager syndrome (NS; see this term) such as microcephaly, blepharophimosis, microtia, a peculiar beakednose, cleft lip and palate, symmetrical involvement of the thumbs and great toes and developmental delay. It has since been suggested that these features can also be a part of the NS phenotype. 